\title{
GCU
}

Glasgow Caledonian

University

University for the Common Good

\section{Mechanistic and ecotoxicological studies of amoxicillin removal through anaerobic degradation systems}

Busto, Raquel Viera; Roberts, Joanne; Hunter, Colin; Escudero, Ania; Helwig, Karin; Coelho, Lucia Helena Gomes

Published in:

Ecotoxicology and Environmental Safety

DOI:

10.1016/j.ecoenv.2020.110207

Publication date:

2020

Document Version

Author accepted manuscript

Link to publication in ResearchOnline

Citation for published version (Harvard):

Busto, RV, Roberts, J, Hunter, C, Escudero, A, Helwig, K \& Coelho, LHG 2020, 'Mechanistic and

ecotoxicological studies of amoxicillin removal through anaerobic degradation systems', Ecotoxicology and Environmental Safety, vol. 192, 110207. https://doi.org/10.1016/j.ecoenv.2020.110207

\section{General rights}

Copyright and moral rights for the publications made accessible in the public portal are retained by the authors and/or other copyright owners and it is a condition of accessing publications that users recognise and abide by the legal requirements associated with these rights.

Take down policy

If you believe that this document breaches copyright please view our takedown policy at https://edshare.gcu.ac.uk/id/eprint/5179 for details of how to contact us. 
1 Mechanistic and Ecotoxicological Studies of Amoxicillin Removal

2 Through Anaerobic Degradation Systems

3

4 Raquel Vieira Busto ${ }^{1}$, Joanne Roberts ${ }^{2}$, Colin Hunter $^{2}$, Ania Escudero ${ }^{2}$, Karin 5 Helwig $^{2}$, Lúcia Helena Gomes Coelho ${ }^{1 *}$

6

7

${ }^{1}$ Universidade Federal do ABC. Avenida dos Estados, 5001. Bairro Santa Terezinha. CEP: 09210580. Santo André - SP, Brazil.

${ }^{2}$ Glasgow Caledonian University. 70 Cowcaddens Road Glasgow, G4 0BA United Kingdom.

* Correspondent author: raquel.busto@aluno.ufabc.edu.br

\section{ABSTRACT}

Many studies have been conducted on the evaluation and monitoring of micropollutants and by-products in wastewater treatment plants. Considering the increase in the production and consumption of emerging contaminants, such as drugs, personal care products, and plasticisers, it is necessary to conduct studies that support the elaboration of laws and regulations that promote the environmentally sustainable use of sludge and effluents. In this work, the biological degradation of amoxicillin was studied under two anaerobic conditions: i) using a $6 \mathrm{~L}$ reactor operated under semi-continuous flow; and ii) a batch system with $100 \mathrm{~mL}$ sealed glass syringes. According to the statistical analysis, amoxicillin was completely removed from the systems, but biogas production inhibition was observed $(p<0.05)$. Liquid chromatography-high-resolution mass spectrometry analysis identified amoxicillin penicilloic acid, amoxilloic acid, amoxicillin diketopiperazine and phenol hydroxypyrazine as by-products under anaerobic conditions. Ecotoxicity tests on effluent treated under the batch conditions showed that the addition of higher amounts of amoxicillin inhibited the target species Aliivibrio fischeri and Raphidocelis subcaptata, causing functional decreases of $28.5 \%$ and $22.2 \%$ when the antibiotic concentration was $2,500 \mu \mathrm{g} \mathrm{L}^{-1}$. A. fischeri was the most sensitive organism to effluent treated under semi-continuous flow conditions; a continuous reduction in bioluminescence of up to $88.8 \%$ was observed after 39 days of feeding, which was associated with by-products accumulation due to unbalanced conditions during anaerobic digestion. Changes in the physico-chemical characteristics of the effluent 
caused the accumulation and removal of AMX-DKP IV and modified the toxicity to Lactuca sativa and $R$. subcapitata.

Keywords: Pharmaceuticals; Anaerobic Biodegradation; LC-HRMS; Aliivibrio fischeri; Lactuca sativa; Raphidocelis subcaptata

\section{INTRODUCTION}

Urban lifestyles, characterised by the high consumption of drugs (such as analgesics, antibiotics, lipid regulators, anti-inflammatories, and synthetic hormones), personal care products, surfactants, and plasticisers, render domestic wastewater one of the main routes for the transfer of emerging contaminants to the environment. The main characteristics of these pollutants are their persistence and nonbiodegradability (refractory substances). These compounds have been the subject of many monitoring studies since they were first detected in treated water, effluent, sediments, surface water, and even underground water, indicating the low removal efficiency of conventional wastewater treatment plants (WWTPs) for these compounds (Petrović et al., 2014; Salgado et al., 2010; Simazaki et al., 2015).

One class of micropollutants, i.e., antibiotics, has received special attention from the scientific community as they may disturb the physiological functions of WWTP microbiota and agricultural soils, and risk promoting the development of resistant microorganisms (Aydin, 2015). Among the antibiotics, amoxicillin is widely consumed worldwide. It is a semi-synthetic penicillin class ( $\beta$-lactam antibiotics) drug used in the treatment and prevention of bacterial respiratory, gastrointestinal, urinary, and skin infections in humans and animals (Bush, 2003; Rao et al., 2011). In the excretion of amoxicillin, over $80 \%$ of the drug is eliminated as the parent compound (Hirsch, 1999). Although its consumption is widespread, little information about the levels of amoxicillin found in waste and surface water has been published in the literature. This can be explained by the instability of the $\beta$-lactam ring in amoxicillin, which readily undergoes hydrolysis after excretion, producing by-products that are not always evaluated in the monitoring of this compound.

Usually, anaerobic digesters are widely applied in the treatment of solid wastes, including sludge from WWTPs, however, the application becomes advantageous in the treatment of sanitary sewage specially in countries of tropical climate when using 
67 UASB type reactors. This kind of technology not only generates biogas that can be used as energy supply but also allows the reduction of the effluent treatment plant total size, the energy consumption and sludge production. In this sense, anaerobic degradation technologies are a cost-effective alternative for wastewater treatment. However, the process may be affected by the presence of toxic compounds, such as antibiotics, reducing the production of biogas or modify the production and conversion of volatile fatty acids (Fountoulakis et al., 2008; Meng et al., 2015), which would then cause the accumulation of several intermediates that inhibit the microbial communities responsible for pollutant degradation.

It should also be noted that international legislation on the disposal of pollutants in treated effluent provides maximum concentration limits for few potential pollutants compounds. Furthermore, there is no concern regarding the quantification of byproducts derived from physico-chemical and biological processes that occur before, during, or after wastewater treatment, which can be as toxic as the original drug. Amoxicillin has only recently been included in the European Union Watch List as a target compound for monitoring its risk to the aquatic environment (Loos et al., 2018). However, the inclusion of amoxicillin and other compounds that are produced and consumed by the populationis limited when conventional analytical methods (such as liquid chromatography) are followed. Thus, further information regarding the effluent treatment efficiency and composition is required.

The novelty of this work lies in the evaluation of amoxicillin degradation under anaerobic conditions and by-products formation and accumulation, whose estimated concentration were confronted to ecotoxicity analyzes performed with species from three different trophic levels. Usually studies concerning on removal of pollutants do not give attention to the formation of by-products (Çelebi and Sponza, 2012; Meng et al., 2015; Rizzo et al., 2009) which can be responsible for more pronounced toxic effects than those of the parent compound. Within this, ecotoxicological assays come as an advantageous technique in order to monitor the performance of WWTPs, providing information about trouble-shooting in case of failures in biological treatment and evaluating environmental risk regarding treated effluent discharge or even in subsequent/ tertiary treatments. 


\subsection{Source of Seed Sludge}

Mesophilic seed sludge was collected in plastic containers from a mesophilic anaerobic digestion treatment plant (Dunns Wood Road, Wardpark South Industrial Estate, Cumbernauld, Scotland). The facility is jointly operated by Paragon-e and Shanks Waste Management Ltd., and treats animal by-products, general food waste, and waste produced by the food processing industry in an anaerobic digester (AD).

\subsection{Synthetic Wastewater}

Synthetic wastewater created following Souza and Foresti (2013),Torres (1992) and Van Loosdrecht et al. (2016) was used in the experiments. A synthetic matrix was selected to control the physico-chemical characteristics throughout the test period with a chemical composition similar to that of domestic wastewater, ensuring the presence of macro- and micronutrients for the anaerobic microbiota. Table S1 presented in the Supplementary Material shows the typical composition of synthetic wastewater used in this work. All reagents used were analytical grade from Aldrich, Acros or Fisher Scientific brands.

\subsection{Batch Tests for Determining the Anaerobic Degradability}

Tests were conducted to determine the anaerobic biodegradation of amoxicillin (Acros, 96\%) according to ISO 11734 (1995) with $100 \mathrm{~mL}$ glass syringes filled with synthetic effluent containing the target compound AMX. Each syringe was filled with $120 \mathrm{mg}$ of organic carbon (synthetic wastewater) and $500 \mathrm{mg}$ of volatile solids (inoculum) to produce a final ratio of 0.2 . For that, synthetic wastewater and $A M X$ concentrations chosen in this study $\left(250,2,500\right.$, and $\left.25,000 \mu \mathrm{g} \mathrm{L}^{-1}\right)$ were prepared 10 times concentrated (i.e., final concentrations of $A M X$ ranged from 2,500 to $\left.250,000 \mu \mathrm{g} \mathrm{L}^{-1}\right)$. These concentrations were chosen based on previous ecotoxicity results of Di Nica et al. (2017) and Magdaleno et al. (2015). Nitrogen was later bubbled into the system for $30 \mathrm{~s}$ to create anaerobic conditions. The syringes were then sealed with a plunger (greased with Vaseline to facilitate movement and prevent gas leakage) and incubated at $37 \pm 1^{\circ} \mathrm{C}$ for 28 days. The syringes were mixed to homogenise the contents before each measurement.

Two control experiments were conducted: one containing only the inoculum (blank), and the other containing polyethylene glycol $\left(7 \mathrm{~g} \mathrm{~L}^{-1}\right)$ as a reference 
133 substrate. This compound is easily biodegradable, and the test is considered valid if 134 the reference is degraded over $60 \%$. The biodegradability was estimated by means 135 of Equation 1:

$$
\text { Biodegradability }(\%)=\frac{\left(V_{t}-V_{c}\right) \times 0.039}{m m o l \text { added }} \times 100
$$

where $V_{t}$ is the volume of biogas measured at day $t$ and $V_{c}$ is the measured volume of control at day $\mathrm{t}$ and $\mathbf{0 . 0 3 9}$ is the conversion factor obtained from ideal gas equation.

\subsection{Anaerobic Digester (BioStat)}

The AD was operated at $37.0 \pm 0.1^{\circ} \mathrm{C}$ throughout the study period under semicontinuous flow. The system was filled with the inoculum (1.05 L) and synthetic wastewater ( $4.95 \mathrm{~L})$ to obtain a final volatile solids content of $4 \mathrm{~g} \mathrm{~L}^{-1}$. After 18 days, the reactor was fed with a hydraulic retention time (HRT) of six days (start-up/ first phase, data not shown). After the stabilisation phase (22 days), the reactor was fed with synthetic wastewater at a HRT of three days, followed by the control/ second phase, which was maintained for 32 days prior to the addition of amoxicillin (third phase). An amoxicillin concentration of $1 \mathrm{mg} \mathrm{L}^{-1}$ was selected to improve the detectability of by-products in LC-HRMS analysis and allows correlation with ecotoxicological studies. It must be stated that interpretation of results are quite different from that expected in real WWTP considering that usual concentrations of amoxicillin in wastewater are in the order of $10 \mathrm{\mu g} \mathrm{L}^{-1}$ (Mutiyar and Mittal, 2013; Verlicchi et al., 2012). On the $58^{\text {th }}$ feeding day, $\mathrm{pH}$ dropped to 6.5 and $\mathrm{NaHCO}_{3}$ was used to increase the value to approximately 7.2 .

The physico-chemical variables of $\mathrm{pH}$, alkalinity, total ammonia nitrogen (TAN), chemical oxygendemand (COD), total and volatile solids (TS and VS), and biogas production were monitored during the experiments following the Standard Methods for the Examination of Water and Wastewater (APHA, 2012).

\subsection{Ecotoxicological Tests}

For these assays, batch syringe samples were diluted at a ratio of 1:10 prior to analysis while the samples from biostat were used as collected, without any dilution. 
166 Three species from different trophic levels were select to evaluate ecotoxicity of 167 wastewater before and after anaerobic treatment. Seed Germination test, Aliivibrio 168 fischeri and Raphidocelis subcapitata were chosen due its advantages in terms of simplicity, cost effectively, reproducibility and low time to obtain the results. A. fischeri is a very sensitivity specie that has been widely used for wastewater monitoring and can be applied for a large number of compounds, including amoxicillin (Çelebi and Sponza, 2012; Di Nica et al., 2017).

173

\subsubsection{Seed Germination and Root Growth Method}

The analysis was performed according to USEPA (1996). For each test sample, a circle of blotting paper $\left(150 \mathrm{~g} \mathrm{~m}^{-2}\right)$ was placed into the lids of $90 \mathrm{~mm}$ Petri dishes with $2 \mathrm{~mL}$ of the sample (analysis was conducted in triplicate). Between 10 and 12 seeds of lettuce (Lactuca sativa), which is commonly cultivated worldwide, were placed in a line three-quarters from the bottom of the blotting paper in each Petri dish. A positive control sample with reconstituted water $\left(294.0 \mathrm{mg} \mathrm{L}^{-1}\right.$ $\mathrm{CaCl}_{2} .2 \mathrm{H}_{2} \mathrm{O}, 122.8 \mathrm{mg} \mathrm{L}^{-1} \mathrm{MgSO}_{4} .7 \mathrm{H}_{2} \mathrm{O}, 64.8 \mathrm{mg} \mathrm{L}^{-1} \mathrm{NaHCO}_{3}$ and $5.8 \mathrm{mg} \mathrm{L}^{-1} \mathrm{KCl}$ ) (OECD, 2004) was tested in duplicate. Each Petri dish was wrapped in cling film and placed in a semi-vertical position in a $25 \pm 1^{\circ} \mathrm{C}$ incubator. After four days of incubation, the Petri dishes were examined, and the number and individual root length of germinated seeds were measured using a vernier calliper (resolution of $0.05 \mathrm{~mm})$.

\subsubsection{Marine bacteria Aliivibrio fischeri}

Acute toxicity tests were conducted using Aliivibrio fischeri according to ISO 11348-3 (2007). Prior to conducting the ecotoxicological assays, samples were diluted (1:10) with $\mathrm{NaCl}$ solution to obtain a $2 \%(\mathrm{w} / \mathrm{v})$-salinity medium. The reference substance (negative control), potassium dichromate, was prepared by adding $0.653 \mathrm{~g}$ of $\mathrm{K}_{2} \mathrm{Cr}_{2} \mathrm{O}_{7}$ to $100 \mathrm{~mL}$ of deionised water and, from that, a 1:100 dilution was obtained using a $2 \%(\mathrm{w} / \mathrm{v}) \mathrm{NaCl}$ solution. Reconstituted water was used as the positive control. Freeze-dried $A$. fischeri was activated by rehydration using the "BioFixLumi Medium" (both from Macherey-Nagel GmbH \& Co. KG). During the test, vials were put into an incubator at $15 \pm 1^{\circ} \mathrm{C}$. Approximately $100 \mu \mathrm{L}$ of the bacterial suspension and $900 \mu \mathrm{L}$ of each sample were added tothe vials, and the samples 
199 were analysed after $30 \mathrm{~min}\left(\mathrm{I}_{30}\right)$ using a portable luminometer (BioFix Lumi-10, 200 Macherey-Nagel $\mathrm{GmbH} \& \mathrm{Co}$. KG). The gamma value $(\Gamma$, measured as a loss of 201 bioluminescence in relation to positive control) was calculated by means of Equation 202 2:

$$
\Gamma=\frac{I_{30}}{\left(I_{0} f_{k t}\right)} \times 100
$$

204

205

Where $f_{k t}$ is the correction ratio for positive control and $I_{30} / I_{0}$ is the bioluminescence 206 ratio measured at 30 and 0 min.

\subsubsection{Algae Raphidocelis subcapitata}

Algae assays were conducted following OECD (2011). A culture containing approximately $10^{7}$ cells $\mathrm{mL}^{-1}$ of Raphidocelis subcapitata (from Culture Collection of

211 Algae and Protozoa - CCAP 278/4, Scotland, U.K.) was prepared in Jaworski medium and used after three days by $1: 10$ dilution in the samples to obtain a final concentration of $10^{6}$ cells $\mathrm{mL}^{-1}$. During the tests (conducted in quadruplicate), samples were constantly shaken at $120 \mathrm{rpm}$ to ensure tha the algae remained in suspension and facilitate $\mathrm{CO}_{2}$ transfer. The temperature was set at $21 \pm 1^{\circ} \mathrm{C}$, and the light intensity was $3500 \pm 350$ lux. Measurements were taken after $96 \mathrm{~h}$ and the cells were counted using a microscope (Brunel Microscopes, Model N-300M) and a cytometer (Celeromics).

\subsection{LC-HRMS Analysis}

\subsubsection{LC-HRMS Conditions}

The presence of amoxicillin and its by-products were analyzed using liquid 224 chromatography coupled to a high resolution mass spectrometer (LC-HRMS) Thermo 225 Scientific Q-Exactive Orbitrap fitted with a Dionex Ultimate 3000 RS Pump, Dionex 226 Ultimate $3000 \mathrm{RS}$ autosampler (temperature controlled at $10^{\circ} \mathrm{C}$ ) and Dionex Ultimate 2273000 RS column compartment (temperature controlled at $30^{\circ} \mathrm{C}$ ) (all from Thermo 228 Fisher Scientific, Hemel Hempstead, England). The mass spectrometer was fitted 229 with an electrospray ion source (ESI) operated in positive ion mode. The nitrogen 230 sheath and auxiliary gas were set at 45 and 10 arbitrary units, respectively. The spray voltage was $+3.5 \mathrm{kV}$ and the ion source temperature $300^{\circ} \mathrm{C}$. The full MS 
experiment scan range was $m / z=150$ to 1500 , with the resolution set at 17500 . The product ion experiment $\left(\mathrm{MS}^{2}\right)$ was conducted using a mass resolution of 17500 . The isolation window for the product ion experiment was $2.0 \mathrm{~m} / \mathrm{z}$ with a normalised collision energy (NCE) of $35 \mathrm{eV}$. A Waters (Elstree, UK) $\mathrm{C}_{18}$ column $150 \times 2.1 \mathrm{~mm}$, particle size $3 \mu \mathrm{m}$ was used for chromatographic separation.

The organic solvent was methanol (A) (Optima LCMS grade, Fisher Scientific) and the aqueous (B) was deionized water containing $0.1 \%$ formic acid $(98 \%$, Fisher Scientific). A gradient elution technique was used: the initial conditions were $99 \%$ B for $1 \mathrm{~min}$, dropping to $30 \% \mathrm{~B}$ over $12 \mathrm{~min}$ then $1 \%$ B over $1 \mathrm{~min}$. The gradient was maintained at $1 \%$ B for 6 min before returning to $99 \%$ B over 1 min and equilibrating for a further $9 \mathrm{~min}$. The eluent flow rate was $0.2 \mathrm{~mL} \mathrm{~min}^{-1}$.

The software to operate the LC-HRMS system was Tracefinder and for MS interpretation Xcalibur. Prior to analysis the instrument was calibrated in positive ion mode using Pierce LTQ Velos ESI Positive ion calibration solution from Fisher Scientific (Loughborough, England).

A 17-point calibration line for amoxicillin (Sigma Aldrich) was prepared in the range $0.01-2,500 \mathrm{ng} \mathrm{mL}^{-1}$. The calibration points fitting the criteria of $\pm 20 \%$ of the best fit line with a $1 / \mathrm{X}^{2}$ weighting was in the range $25-1,000 \mathrm{ng} \mathrm{mL}^{-1}$.

\subsubsection{Determination of unknown by-products}

An amoxicillin solution was subjected to degradation under acidic conditions and then analysed by LC-HRMS to obtain the retention time and precursor ions of the by-products. Once the precursor ions were established, product ion data were determined for each compound. The concentration of by-products in the samples was estimated from the amoxicillin calibration curve as the standards for these byproducts are not commercially available, and the unknown compounds could ionise differently to amoxicillin. A matrix effect study was conducted (not shown in this work), and found that the compounds present in the synthetic effluent had little influence on the detectability and quantification of amoxicillin. Considering the highly consistent effluent composition and the use of a high-resolution mass spectrometer, isotopically labelled amoxicillin was not used in this study.

\subsection{Statistical Analysis of Results}



266 with a $5 \%$ significance level $(p<0.05)$. All statistical analyses were conducted in 267 OriginPro 9.0 software. The different letters on the tops of each box in the boxplot 268 indicate statistically different data.

\section{RESULTS AND DISCUSSION}

\subsection{Identification of by-products by HRMS}

$272 \quad$ Figure 1 presents the by-products identified in the anaerobic degradation of 273 amoxicillin. According to Nägele and Moritz (2005), the hydrolysis of the $\beta$-lactam 274 ring of amoxicillin produces amoxicillin penicilloic acid (AMXC), which can be further 275 degraded through two different pathways. The first generates amoxilloic acid (AMXO) 276 after the decarboxylation of the free carboxylic acid group, and the second occurs by 277 the formation of a new, stable, six-membered ring, generating amoxicillin 278 diketopiperazine (AMX-DKP). The mechanism of 3-(4-hydroxyphenyl)-2(1H)279 pyrazinone (phenol hydroxypyrazine) formation has not been reported in the 280 literature. Figure 1 shows the precursor and product ions of amoxicillin and the by281 products identified by LC-HRMS analysis. 
Precursor Ion

Amoxicillin

$\left[\mathrm{C}_{16} \mathrm{H}_{20} \mathrm{~N}_{3} \mathrm{O}_{5} \mathrm{~S}+\mathrm{H}\right]^{+}$

Exact mass $=366.1118$

Accurate mass $=366.1124$

Mass error $=1.63 \mathrm{ppm}$

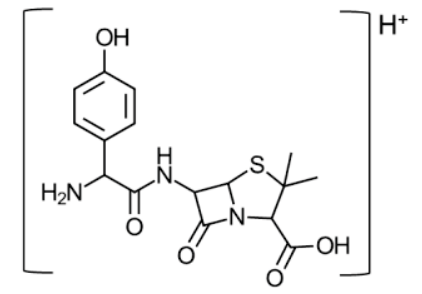

(c)

Amoxicillin penicilloic acid (AMXC)

$\left[\mathrm{C}_{16} \mathrm{H}_{22} \mathrm{~N}_{3} \mathrm{O}_{6} \mathrm{~S}+\mathrm{H}\right]^{+}$

Exact mass $=384.1229$

Accurate mass $=384.1230$

Mass error $=0.26 \mathrm{ppm}$

2 degradation products

\section{Product Ion}

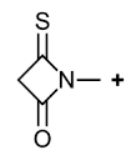

$\mathrm{C}_{4} \mathrm{H}_{4} \mathrm{NOS}^{+}$

Exact mass $=114.00081$

Accurate mass $=114.0014$

Mass error $=5.17 \mathrm{ppm}$<smiles>C[C@H](N)C1NC(C(=O)O)C(C)(C)S1</smiles>

$\mathrm{C}_{7} \mathrm{H}_{13} \mathrm{~N}_{2} \mathrm{O}_{2} \mathrm{~S}^{+}$

Exact mass $=189.0692$

Accurate mass $=189.0694$

Mass error $=0.26 \mathrm{ppm}$
Amoxicillin diketopiperazine (AMX-DKP)

$\left[\mathrm{C}_{16} \mathrm{H}_{19} \mathrm{~N}_{3} \mathrm{O}_{5} \mathrm{~S}+\mathrm{H}\right]^{+}$

Exact mass $=366.1118$ Accurate mass $=366.1124$

Mass error $=1.63 \mathrm{ppm}$

6 degradation products

Amoxilloic acid (AMXO) $\left[\mathrm{C}_{15} \mathrm{H}_{22} \mathrm{~N}_{3} \mathrm{O}_{4} \mathrm{~S}+\mathrm{H}\right]^{+}$ Exact mass $=340.1326$ Accurate mass $=340.1323$ Mass error $=-0.88 \mathrm{ppm}$ 2 degradation products
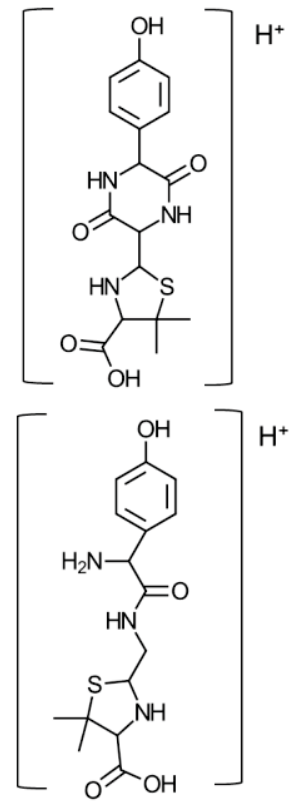<smiles>CC1(C)S[CH]NC1C(=O)O</smiles>

$\mathrm{C}_{6} \mathrm{H}_{10} \mathrm{NO}_{2} \mathrm{~S}^{+}$

Exact mass $=160.04268$ Accurate mass $=160.0428$ Mass error $=0.75 \mathrm{ppm}$

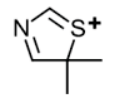

$\mathrm{C}_{5} \mathrm{H}_{5} \mathrm{NS}^{+}$

Exact mass $=114.0372$

Accurate mass $=114.0377$ Mass error $=4.4 \mathrm{ppm}$

$\mathrm{C}_{7} \mathrm{H}_{13} \mathrm{~N}_{2} \mathrm{O}_{2} \mathrm{~S}^{+}$

Exact mass $=189.0692$

Accurate mass $=189.0693$

Mass error $=0.53 \mathrm{ppm}$<smiles>C=CC(=C[CH2+])c1cnccn1</smiles>

$\mathrm{C}_{9} \mathrm{H}_{9} \mathrm{~N}_{2}{ }^{+}$

Exact mass $=145.07602$

Accurate mass $=145.0760$

Mass error $=-0.14 \mathrm{ppm}$

3-(4-Hydroxyphenyl)-2(1H)-pyrazinone
$\left[\mathrm{C}_{10} \mathrm{H}_{9} \mathrm{~N}_{2} \mathrm{O}_{2}+\mathrm{H}\right]^{+}$
Exact mass $=189.0664$
Accurate mass $=189.0660$
Mass error $=-2.11 \mathrm{ppm}$
Amoxicillin Impurity $\mathrm{F}$

Figure 1: Precursor and product ions obtained for amoxicillin and its by-products identified by LC-HRMS analysis.

These results agree with those of Gozlan et al. (2013), Hirte et al. (2016) and 287 Pérez-Parada et al. (2011). The authors observed two different peaks for AMXO, 288 AMX-DKP, and AMXC, which were associated with the corresponding stereoisomers 
289 by the fragmentation pattern. Several by-products with the same precursor ions as 290 amoxicillin were detected in the samples. The amoxicillin retention time was $4.7 \mathrm{~min}$, 291 and the main ion products were observed at 114.0014 and $160.0429 \mathrm{~m} / \mathrm{z}$. The by292 products with the same ion-precursor as amoxicillin had LC retention times of 6.8, 7.1 $2937.5,8.0,8.2$, and $8.5 \mathrm{~min}$. These are likely AMX-DKP or compounds with similar 294 structures. The products also had different ion-product ratios of 160.0428 and $295114.0372 \mathrm{~m} / \mathrm{z}$. Thus, it is possible to distinguish between the AMX and AMX-DKP 296 owing to the high accuracy of the HRMS detector, which produces ion-products with 297 different mass values (accurate and exact), such as the $\mathrm{m} / \mathrm{z}$ ion-product of 114.0008 298 for AMX and 114.0372 for AMX-DKP.

299

\subsection{Batch (Syringe) Tests}

The first set of experiments was conducted with support of glass syringes to estimate the effect of the amoxicillin concentration on the anaerobic degradability and biogas production (Figure S1, see Supplementary Material). The experiment was considered valid once the biodegradability of polyethylene glycol reached $69 \pm 9 \%$ after 21 days.

The ANOVA analysis for $p<0.05$ showed that amoxicillin concentrations of 2,500 and $25,000 \mu \mathrm{g} \mathrm{L}^{-1}$ in the systems only affected the anaerobic process in the first three days of exposure, reducing the biogas production, microbial activity, and effluent biodegradability. Following this, the residual AMX concentration is no more significant than that inthe control system (without any pollutant). However, an amoxicillin concentration of $250,000 \mu \mathrm{g} \mathrm{L}^{-1}$ exerted significant effects for up to 16 days of exposure, even in comparison to other systems containing amoxicillin. Even with the inhibition ofanaerobic digestion caused by high concentrations of amoxicillin,

314 the degradation ability of microorganisms can recover and produce similar quantities 315 of biogas to systems with low amounts or without antibiotics ( $p>0.05$ ). Lallai et al. 316 (2002) obtained similar results from their fermentation batch tests up to $250 \mathrm{~h}$ : the higher the initial concentration of amoxicillin, the lower the methane production. They attributed this result to the inhibitory effects on one or more metabolic bacterial groups active in methane conversion.

The LC-HRMS analysis showed that while no amoxicillin was detected after 28 days, proportional concentrations of the by-products were obtained in the syringes; 
322 the higher the initial concentration of amoxicillin, the higher the final concentration of 323 the by-products. The sum of all by-products corresponded to $26.3 \pm 1.4 \%, 28.1 \pm$ $3243.7 \%$, and $31.2 \pm 2.9 \%$ of the initial pollutant concentration in the systems containing $3252,500,25,000$, and 250,000 $\mathrm{Mg} \mathrm{L}^{-1}$ of amoxicillin, respectively (Figure S2, see 326 Supplementary Material). Andreozzi et al. (2004) demonstrated that both adsorption 327 on sludge and biodegradation play important roles in the transformation and removal 328 of amoxicillin under aerobic conditions, with the latter being more important and rapid 329 in this process. Hirte et al. (2016) showed that hydrolysis plays an important role in 330 the transformation of amoxicillin. After 20 days, under conditions of neutral $\mathrm{pH}$ and 331 temperature of $30^{\circ} \mathrm{C}$, compound AMXC corresponded to approximately $45 \%$, 332 whereas AMX-DKP and AMXO corresponded to less than $10 \%$ each in terms of 333 relative intensity of the peaks detected by liquid chromatography. In fact, these 334 results corroborate the idea that, although AMX is highly susceptible to hydrolysis, its 335 degradation by-products are recalcitrant to biodegradation, possibly being accumulated in reactors from real WWTPs along time.

337 It is also important to draw attention to the fact that the conditions used in this 338 test do not correspond to the optimal conditions of biodegradation, since a dilute 339 sludge is used with a relatively high concentration of test chemical. The results 340 obtained, however, are important for analysis in conjunction with other studies in the 341 literature that assess bacterial resistance to antibiotics and changes in the microbial 342 community. The accumulation of by-products derived from long treatment periods 343 can cause changes in the abundance and diversity of the bacterial population as 344 exposed in the work of Meng et al. (2017) and thus, affect treatment efficiency and 345 effluent toxicity.

346 The ecotoxicological tests with L. sativa (Figure 2) exhibited no inhibition 347 under the increased amounts of amoxicillin in the raw effluent, according to the 348 ANOVA results (Tukey test, $p$ values ranging from 0.54 to 0.99 for seed germination 349 and from 0.17 to 0.97 for root length). Hillis et al. (2011) also concluded that 350 amoxicillin is not toxic to $L$. sativa with an $E_{25}>10,000 \mu \mathrm{g} \mathrm{L}^{-1}$ (effective 351 concentration that causes $25 \%$ inhibition) while Daucus carota (carrot) is more 352 sensitive to the compound, with an $\mathrm{EC}_{25}$ of $9,342 \mu \mathrm{g} \mathrm{L}^{-1}$ for root length. Following 353 treatment, decreases in seed germination and average root length were expected as 354 the initial concentration of amoxicillin and the formation of by-products in the system 
355 increased. However, higher initial concentrations of the antibiotic stimulated the 356 growth of lettuce seeds. A lower initial concentration of amoxicillin $\left(250 \mu \mathrm{g} \mathrm{L}^{-1}\right)$ 357 caused inhibition when compared to the blank, with reductions in seed germination of $35838.5 \%(p=0.0033)$ and average root length of $33 \%(p=0.12)$. An amoxicillin 359 concentration of $2,500 \mu \mathrm{L} \mathrm{L}^{-1}$ also led to reductions in seed germination of $33 \%(p=$ $3600.016)$ and average root length of $37.2 \%(p=0.053)$. This indicates that amoxicillin 361 by-products may be more toxic to this target organism than the amoxicillin itself.

362

363
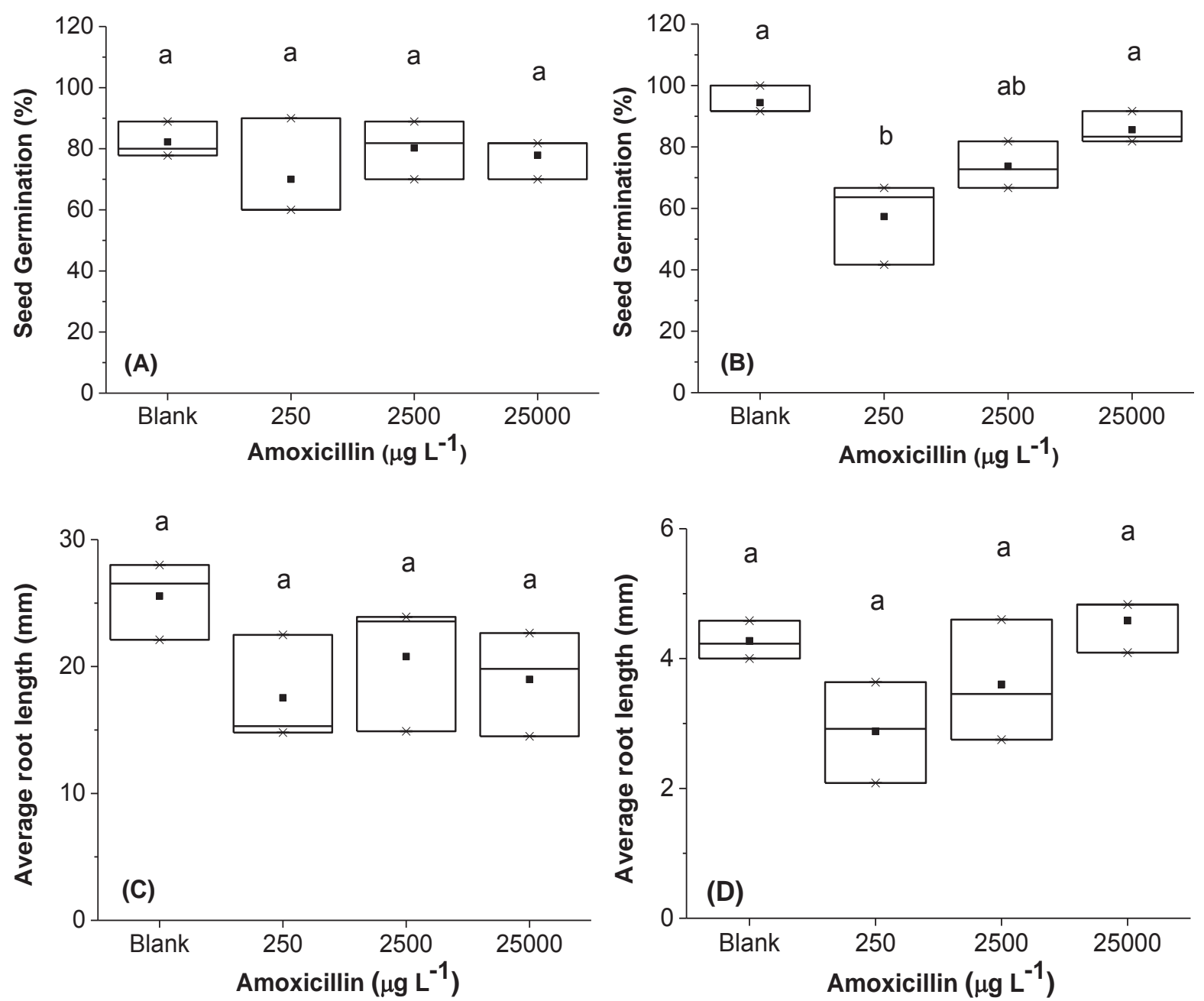

Figure 2: Results for Seed Germination test (specie Lactuca sativa) in the syringes with amoxicillin (28 days). Graphics show Seed Germination for raw (A) and treated (B) effluents and Average Root Length for raw (C) and treated (D) effluents. The different letters on the tops of each boxplot indicate statistically different data according to ANOVA for $p<0.05$.

The results for $A$. Fischeri are shown in Figure 3. With the raw effluent, inhibition of bioluminescence was observed in all systems, including the blank, when 
372 compared to the test substance $(\Gamma=100 \%)$. However, no correlation between 373 bioluminescence and concentrations of amoxicillin was observed in the ANOVA test. 374 An average reduction in luminescence from $41.1 \%$ (blank) to $29.9 \%$ was observed 375 with the addition of antibiotic.

376 For treated samples, an increase in the bioluminescence from $6.9 \pm 0.9 \%$ 377 (blank) to $20.3 \pm 4.2 \%$ was observed with an initial amoxicillin concentration of $37825,000 \mathrm{\mu g} \mathrm{L}^{-1}$ as the amount of by-products increased. The results of the ANOVA test 379 showed that samples from the blank and the system containing $250 \mu \mathrm{g} \mathrm{L}^{-1}$ of amoxicillin exhibited the same level of toxicity to A. Fischeri $(p=0.98)$, while the other samples were less toxic $\left(p=2.41 \times 10^{-4}\right.$ and $4.19 \times 10^{-6}$ for 2,500 and 25,000 $\mu \mathrm{g} \mathrm{L}^{-1}$ of amoxicillin compared to the blank, respectively), indicating that amoxicillin 383 by-products are less toxic to this organism. In the study conducted by Çelebi and 384 Sponza (2012), wastewater treatment using AMCBR (anaerobic multi-chamber bed 385 reactor) and containing $150 \mathrm{mg} \mathrm{L}^{-1}$ of amoxicillin led to a reduction in the $\mathrm{EC}_{50}$ 386 (effective concentration that causes 50\% inhibition) values of $A$. fischeri from 143 387 (influent) to $215 \mathrm{mg} \mathrm{L}^{-1}$ (effluent) with a HRT of 5.5 days. The lower $\Gamma$ than that of the 388 raw effluent could be ascribed to dispersion of luminescent by particles or by the presence of bacteria from the inoculums used in the test.

390
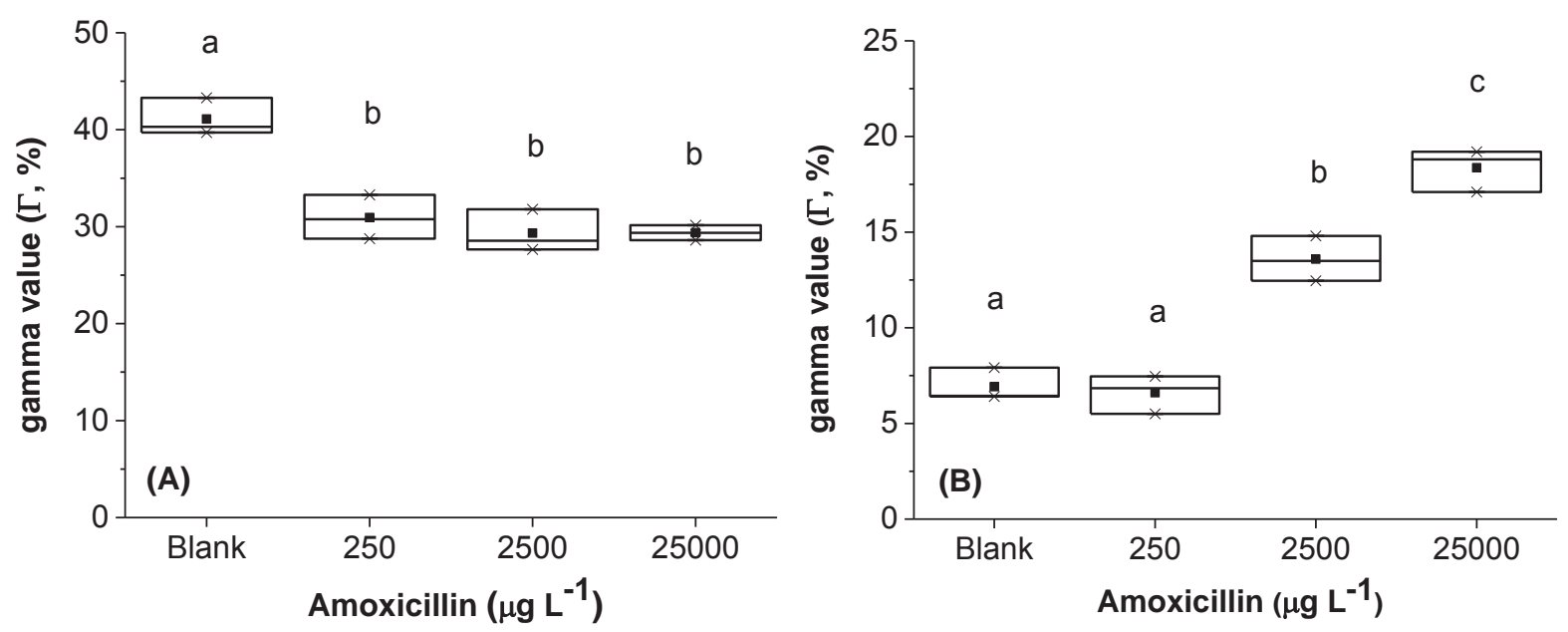

Figure 3: Effect of amoxicillin and its by-products in the Aliivibrio fischeri ecotoxicity after 30 min of exposure for raw (A) and treated (B) effluents after 28 days experiment. The different letters on the tops of each boxplot indicate statistically different data according to ANOVA for 395 $\mathrm{p}<0.05$. 

4). The ANOVA showed statistically different results for systems with amoxicillin concentrations that were two or three orders of magnitude different from each other. 400 In contrast to the study by Andreozzi et al. (2004), where $R$. subcapitata was 401 insensitive to amoxicillin within the range of $50 \mathrm{ng} \mathrm{L}^{-1}$ to $50 \mathrm{mg} \mathrm{L}^{-1}$, the concentration 402 of $25,000 \mu \mathrm{g} \mathrm{L}^{-1}$ used in this study caused a mean reduction in the number of cells of $40330.9 \%$. The authors utilised AMX dilutions in distilled water, while this work presents 404 the effect of antibiotics in a more complex matrix, similar to that of wastewater, 405 demonstrating the matrix effect in this study. However, the presence of by-products 406 in the treated effluent did not appear to affect the algae growth (Figure 4B) unless 407 higher concentrations of by-products are compared $\left(2,500\right.$ and $25,000 \mu \mathrm{L} \mathrm{L}^{-1}, p=$ 408 0.047).

409
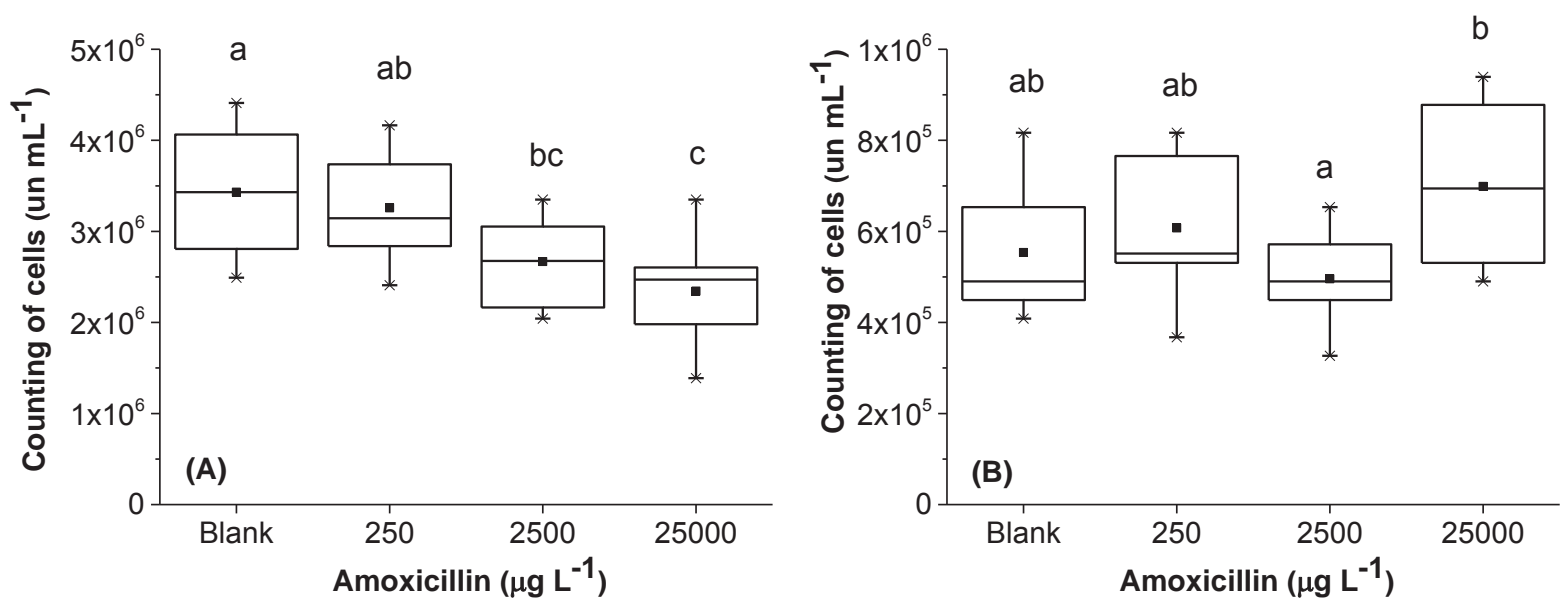

Figure 4: Effect of amoxicillin and its by-products in the Raphidocelis subcapitata cells counting after $96 \mathrm{~h}$ of experiment for (A) raw and (B) treated effluent after 28 days of test. The different letters on the tops of each boxplot indicate statistically different data according to ANOVA for $p<0.05$.

\subsection{Anaerobic Digester (BioStat)}

Figure 5 shows the profiles for $\mathrm{pH}$, alkalinity, biogas production, COD, and TAN in the anaerobic reactor in phases two (control phase) and three (addition of amoxicillin). The influent composition is that described on Table S1 (see Supplementary Material), corresponding to the following characterization: $\mathrm{pH}=7.4$, $\mathrm{COD}=890 \mathrm{mg} \mathrm{L}^{-1}$ and TAN $=36.4 \mathrm{mg} \mathrm{L}^{-1}$. For alkalinity, the titration was executed in two parts: i) titration until pH 5.7 and named bicarbonate/ partial alkalinity $\left(0.26 \mathrm{~g} \mathrm{~L}^{-1}\right)$; 
423 ii) titration between pHs 5.7 and 4.3, giving an estimative of volatile fatty acids and 424 thus named VFA alkalinity $\left(0.07 \mathrm{~g} \mathrm{~L}^{-1}\right)$.
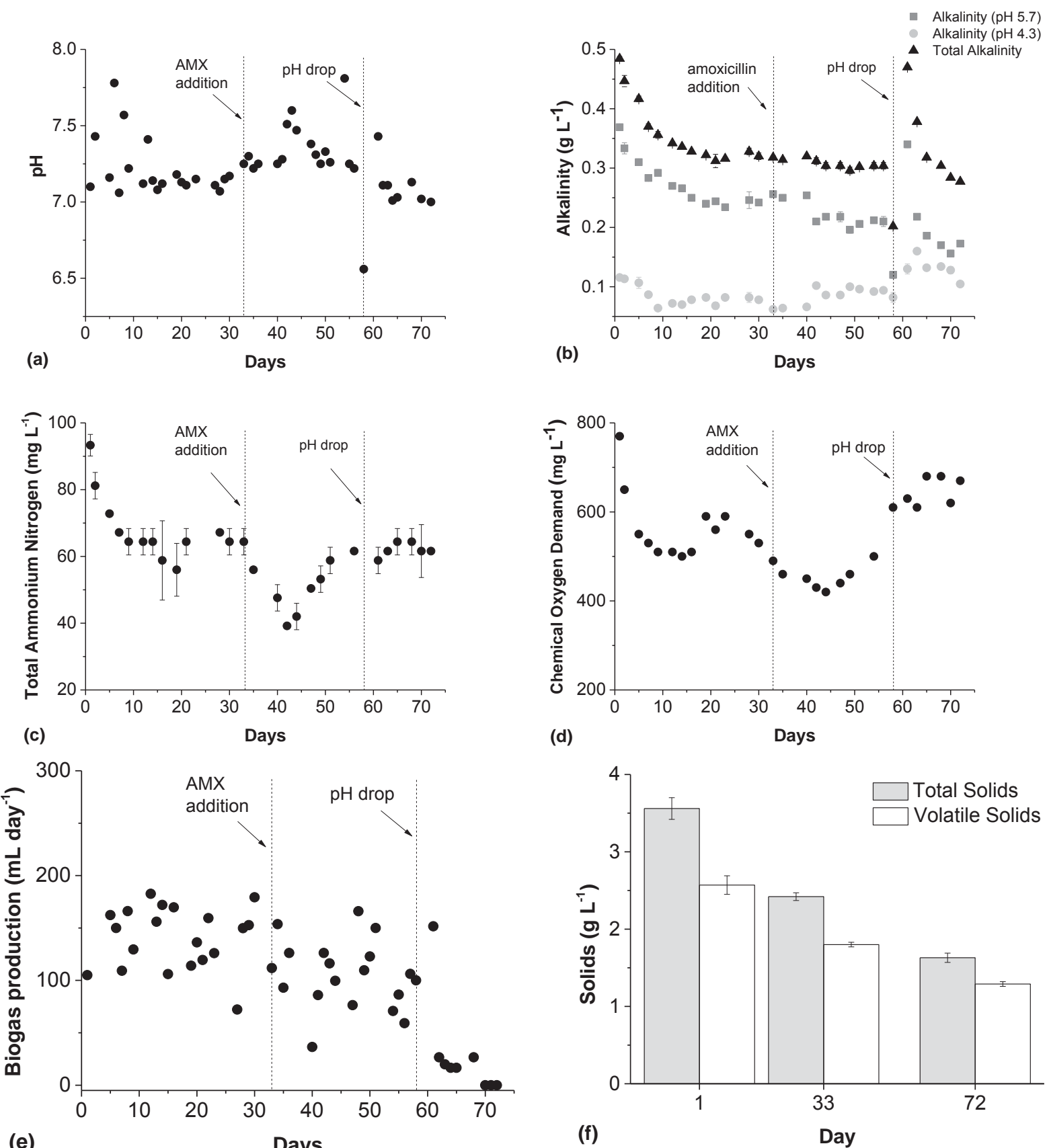

429 Figure 5: Physico-chemical variables monitored along anaerobic digester operation. (a) pH, (b)

430 Alkalinity, (c) Total Ammonium Nitrogen, (d) Chemical Oxygen Demand, (e) Biogas production and (f) Total and Volatile Solids.

The $\mathrm{pH}$ values varied between 7.0 and 7.8 in both systems, but generally 434 remained near $\mathrm{pH}$ 7.2. A decrease to $\mathrm{pH} 6.5$ was observed in the reactor on day 58 435 (as mentioned in section 2.4), but no significant modifications occurred because of 
amoxicillin addition according to ANOVA ( $p=0.155)$, although a peak at $\mathrm{pH}=7.6$ was observed 10 days after the initial addition of AMX to the system (day 43).

The alkalinity decreased from day one until sixteen, and then remained stable until day fifty-eight. This reduction was attributed to the loss of solids at the reactor exit. During the first days, lighter solids, which contribute to the alkalinity of the sample (as ammonium bicarbonate), are drawn out of the reactor. Therefore, at the end of the 16th day, only the denser solids that precipitate in the reactor remain. On day 58 , due to great reduction of $\mathrm{pH}(0.7$ units), the total alkalinity decreased from 0.3 to $0.2 \mathrm{~g} \mathrm{~L}^{-1}$, and $\mathrm{NaHCO}_{3}$ was added to balance the $\mathrm{pH}$ of the system, which caused an increase in total alkalinity to $0.47 \mathrm{~g} \mathrm{~L}^{-1}$ on day 61 . Statistical analysis revealed no difference in the total alkalinity between the phases of operation ( $p$ values ranging from 0.102 to 0.897 ). However, an individual evaluation of the bicarbonate alkalinity ( $\mathrm{pH} \mathrm{5.7)} \mathrm{and} \mathrm{VFA} \mathrm{alkalinity}(\mathrm{pH} \mathrm{4.3)} \mathrm{showed} \mathrm{that} \mathrm{the} \mathrm{addition} \mathrm{of}$ AMX caused a mean reduction in the bicarbonate alkalinity of $20.1 \%(p=0.021)$, while after $\mathrm{pH}$ reduction there was an increase in the VFA alkalinity of $42.0 \%$ from that of the system with amoxicillin $(p=0.0012)$. These results indicate that the additions of the antibiotic and $\mathrm{pH}$ reduction (even after correction with $\mathrm{NaHCO}_{3}$ ) created unbalanced conditions during anaerobic digestion.

Analysis showed that AMX caused a mean reduction in COD from $560 \pm 74 \%$ to $456 \pm 28 \%$ in relation to that in the control phase, demonstrating that AMX stimulated the biodegradation of the effluent $\left(p=9.52 \times 10^{-4}\right)$ in a first moment possibly by supplying easily degradable carbon sources like formic acid through the decarboxylation of AMXC to form AMXO. The average biogas production did not change ( $p=0.371$ ) for second and third phases: from day one to thirty-three (control phase) mean production was $148 \pm 49 \mathrm{~mL} \mathrm{day}^{-1}$, while that in the period from day 33 to 58 was $107 \pm 33 \mathrm{~mL} \mathrm{day}^{-1}$. After day 58 , reduction of $\mathrm{pH}$ was followed by the increase in COD values (with mean COD removal of only $27.8 \%$ ), which culminated with a reduction in biogas production until no biogas was released. This can be attributed to the accumulation of volatile fatty acids, represented by a rapid decrease in total alkalinity from 0.47 to $0.30 \mathrm{~g} \mathrm{~L}^{-1}$ and an increase in the VFA alkalinity, as shown previously.

TAN values were also modified in third phase when AMX was present. The 468 mean value was reduced from $68.9 \pm 11.2 \mathrm{mg} \mathrm{L}^{-1}$ to $52.0 \pm 8.6 \mathrm{mg} \mathrm{L}^{-1}(p=9.36 \times$ 
$46910^{-7}$ ), but this result is more related to $\mathrm{pH}$ changes and equilibrium between $\mathrm{NH}_{4}^{+} /$ $470 \mathrm{NH}_{3}$ and not $\mathrm{AMX}$ presence. The $\mathrm{pH}$ reduction on day 58, on the other hand (and its 471 subsequent correction with $\mathrm{NaHCO}_{3}$ ), did not modify ammonia concentration $472(p<0.05)$. Considering that influent TAN value was $36.4 \pm 3.9 \mathrm{mg} \mathrm{L}^{-1}$, which is lower 473 than that after treatment, it is verified an increase in the amount of ammonia occurred 474 during anaerobic digestion through the breakdown of organic nitrogen and its 475 subsequent conversion into ammonia, which confirms that the system was 476 anaerobic. The high HRT associated with the low amount of carbohydrates added to 477 the system, also culminated in a reduction in the solid content of the anaerobic 478 digester. Average reductions in the total and volatile solid contents of $54.2 \%$ and $47949.8 \%$ were observed after 72 days of operation, respectively.

480 The samples analysed by HRMS showed the accumulation of several by481 products identified in the degradation of amoxicillin (Figure S3, see Supplementary 482 Material). An accumulation followed by removal was observed only for AMX-DKP IV. 483 Amoxicillin was observed in the first two days after its initial addition, with a maximum 484 estimated concentration of $0.0068 \mu \mathrm{mol} \mathrm{L} \mathrm{L}^{-1}$ confirming its rapid hydrolysis. The main 485 observed by-product was amoxicillin penicilloic acid II (AMXC II). After 18 days, its 486 concentration reached $1.58 \mu \mathrm{mol} \mathrm{L}^{-1}\left(604.4 \mu \mathrm{g} \mathrm{L}^{-1}\right)$, corresponding to $57.6 \%$ of AMX 487 influent concentration $\left(2.74 \mu \mathrm{mol} \mathrm{L}{ }^{-1}\right)$. AMXC was also found in a higher relative 488 proportion than other by-products in monitored WWTPs and laboratory scale studies 489 (Gozlan et al., 2013; Hirte et al., 2016). For AMX-DKP IV its maximum concentration $490\left(0.0264 \mu \mathrm{mol} \mathrm{L}{ }^{-1}\right.$ or $\left.9.6 \mu \mathrm{g} \mathrm{L}^{-1}\right)$ was observed on the ninth day after the addition of 491 amoxicillin, and then decreased to almost $0.0055 \mu \mathrm{mol} \mathrm{L}{ }^{-1}$. After 40 days of feeding 492 the sum of all by-products corresponded to $76 \%$ of the total AMX added to biostat. 493 The formation of AMX-DKP IV was associated with changes in COD, TAN, and $\mathrm{pH}$, 494 as its maximum observed concentration in BioStat coincided with the maximum $\mathrm{pH}$ 495 value, maximum removal of COD but minimum concentration of ammonia nitrogen 496 due to increased $\mathrm{pH}$ in this period (see Figure S4 from Supplementary Material).

497 The presence of phenol hydroxypyrazine as a by-product of amoxicillin 498 degradation was not observed during the syringe tests. On the other hand, in the 499 studies conducted with the semi-continuous flow reactor, the compound was 500 observed in concentrations lower than $0.011 \mu \mathrm{mol} \mathrm{\textrm {L } ^ { - 1 }}$ when then, after the $\mathrm{pH}$ drop 501 on the 25th day of feeding with $\mathrm{AMX}$, its concentration rapidly raised from 0.0073 to 
$5020.011 \mu \mathrm{mol} \mathrm{L}{ }^{-1}$ and then to more than $0.089 \mu \mathrm{mol} \mathrm{L}^{-1}$ in the subsequent days (Figure $503 \mathrm{~S} 3 \mathrm{e}$ ). The appearance of phenol hydroxypyrazine after $\mathrm{pH}$ drop is in agreement with 504 the study of Hirte et al. (2016) where it was observed the preferential formation of 505 compound at acidic conditions. Gozlan et al. (2013) associated the appearance of 506 phenol hydroxypyrazine with the major abundance of AMXC.

507 The accumulation of by-products can be explained due to unbalanced 508 conditions observed in physico-chemical parameters. The low HRT used in this study 509 was not enough for the complete mineralization of the compounds generated during 510 the anaerobic treatment. Besides the reduction in COD after addition of amoxicillin, 511 this value did not exceed $50 \%$, indicating the low removal efficiency of the system. 512 Çelebi and Sponza (2012) observed a reduction in the removal of amoxicillin and 513 COD when HRTs as low as 1.13 days were used. They attributed this to the 514 insufficient time available for the mineralisation of COD, amoxicillin, and its 515 metabolites owing to the inadequate conditions for mass transfer into the granules of 516 the AMCBR. Another reason for the decrease in the treatment efficiency was the 517 partial inhibition of microorganisms by amoxicillin, resulting in lower methanogenic 518 activity and deficiencies in the metabolization of volatile fatty acids. During this study, 519 there was an increase in the VFA/ bicarbonate alkalinity ratio of 0.30 (system without $520 \mathrm{AMX}$ ) to 0.39 (after addition of $\mathrm{AMX}$ ) and then to 0.64 after 58 days of reactor 521 operation, indicating in fact the occurrence of anaerobic reactor disturbances. Meng 522 et al. (2015) also observed an increase in the concentration of volatile acids as the 523 concentration of AMX in the influent was increased. This result may be related to the 524 formation and accumulation of more recalcitrant molecules of amoxicillin by-products, 525 as they require longer periods for biodegradation. Although this work has employed 526 high concentrations of drug, the results point to the fact that long periods of operation 527 with effluents containing this type of compound can cause system failure and 528 consequent death of the biomass.

529 On the other hand, the process of adsorption of these compounds to the 530 biomass cannot be ignored. Marcelino et al. (2016) observed a removal of $80 \%$ of 531 amoxicillin present in a pharmaceutical wastewater after 28 days of aerobic 532 biodegradation, however desorption tests were carried out and the results showed 533 that after 12 days at least $54 \%$ of amoxicillin were desorbed from the sludge. With 
534 this, it is clear the possibility of drug accumulation in real WWTPs and attention 535 should be paid to the use of sludge as a source of biofertilizer in agriculture.

Among the target organisms used in the ecotoxicity assays, Aliivibrio fischeri

538 was the most sensitive to the degradation by-products of amoxicillin in the treated 539 effluent samples (Figure S5, see Supplementary Material). The effluent collected 540 after 39 days was $89 \%$ more toxic than that obtained before the addition of 541 amoxicillin. This result disagrees with that observed for the syringe samples, in which 542 higher by-product concentrations were less toxic to $A$. fischeri. In this case, the 543 presence of AMXO II and the formation of AMX-DKP I, II, III, V, and VI were not 544 observed, which could positively stimulate the bioluminescence. The preferential 545 formation of AMX-DKP in the syringes could be attributed to the higher $\mathrm{pH}$ 546 (approximately 7.8 at the end of the experiment) in comparison to $\mathrm{pH}$ values 547 observed in BioStat (average of 7.3). At higher $\mathrm{pH}$ values, the amine group is 548 deprotonated $\left(\mathrm{p} K_{\mathrm{a}}=7.56\right)$, thus it is available for a nucleophilic attack on the carbonyl 549 group to create a diketopiperazine ring as observed by Gozlan et al. (2013). A. 550 fischeri was also the most sensitive species in the study by Çelebi and Sponza 551 (2012), who observed an increase in the toxicity when the HRT was reduced to 0.9 552 days, which resulted in a reduction in the biogas production and an increase in the 553 volatile fatty acids concentration that could enhance the effluent toxicity.

554 The ecotoxicological assays conducted using lettuce seeds (Figure 6) showed 555 that the seeds are sensitive to the presence of AMX-DKP IV. While the toxicity of the 556 samples increased from the first day to day 11 (observed by the reduction in the 557 calculated indexes), as the concentration of amoxicillin by-products increased in the 558 effluent, the toxicity was lower on day 18 and the concentration of AMX-DKP IV was 559 also reduced, even with the successive accumulation of other by-products. 


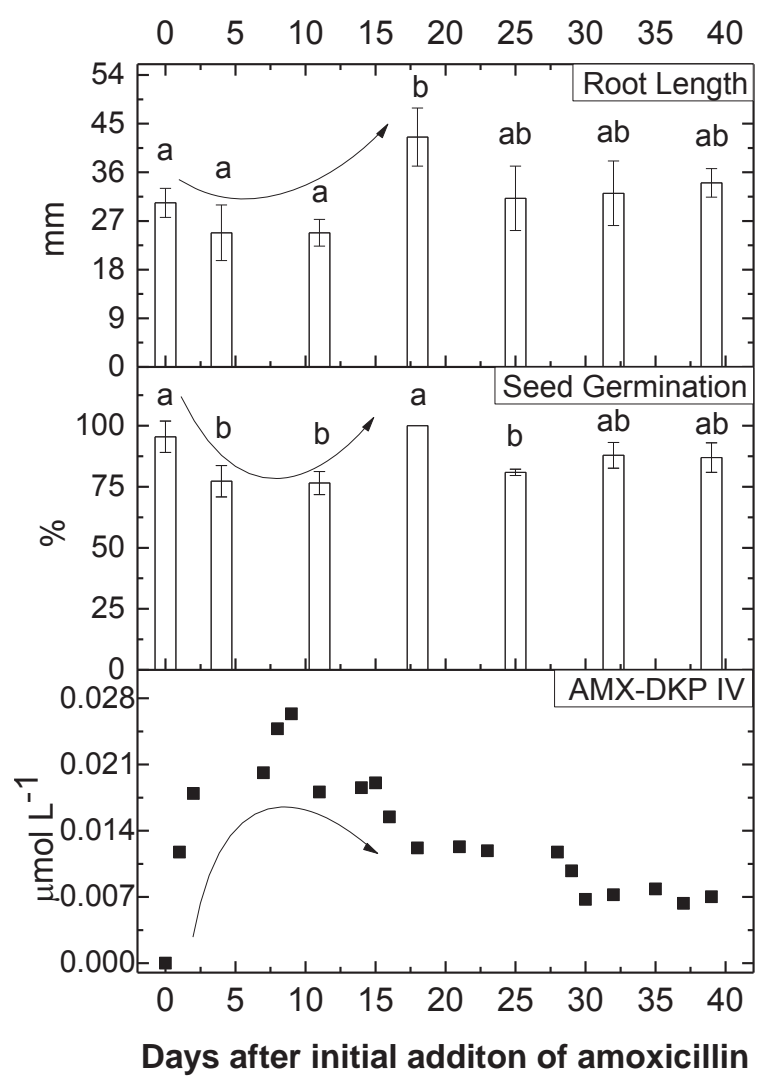

Figure 6: Results Seed Germination tests for samples after anaerobic treatment. Time zero represents the treated effluent before the addition of compounds. The different letters on the tops of each bar indicate statistically different data according to ANOVA for $p<0.05$.

The opposite behaviour was observed in the test with $R$. subcapitata. The 566 formation of AMX-DKP IV coincided with the stimulation of algae cells until day 11, 567 and then decreased until day 25 . On days 32 and 39, further stimulation was 568 observed, which coincided with the formation of phenol hydroxypyrazine (Figure 7). 


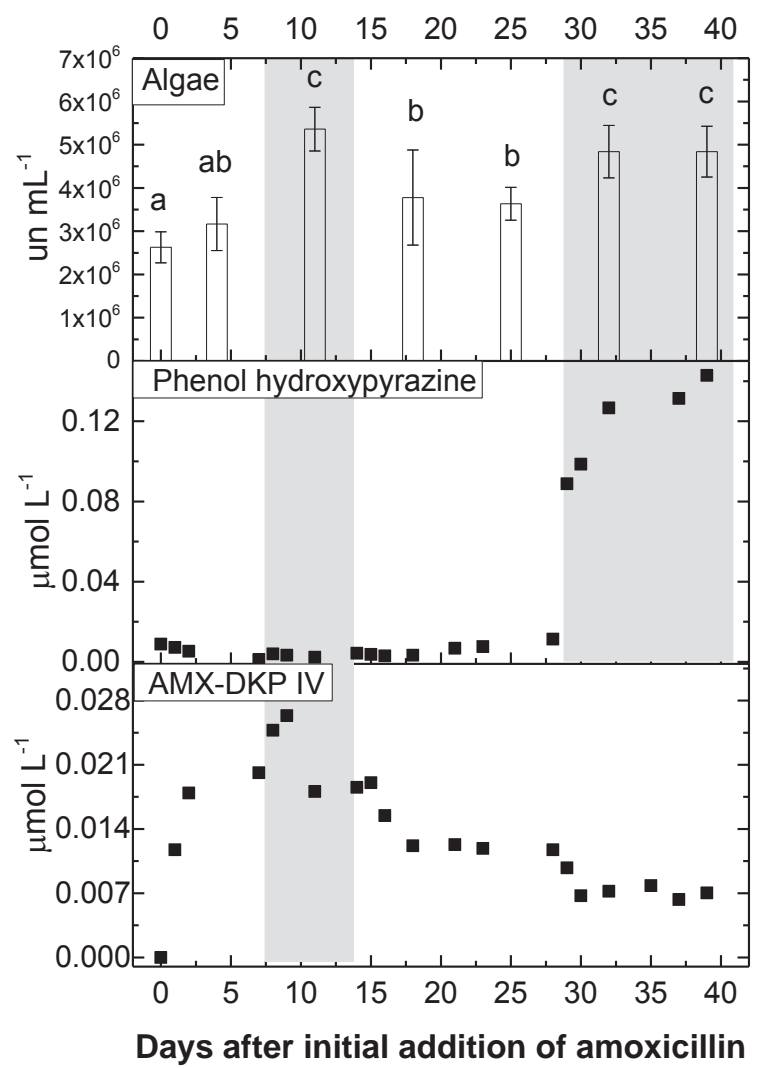

Figure 7: Effect of anaerobic treatment in Raphidocelis subcapitata cells counting after $96 \mathrm{~h}$ of

572 experiment. Time zero represents the treated effluent before the addition of amoxicillin. Grey 573 shadows identify where it was observed a correlation between formation of AMX-DKP IV and 574 Phenol hydroxypyrazine and modifications in counting of algae cells. The different letters on

575 the tops of each bar indicate statistically different data according to ANOVA for $p<0.05$.

\section{CONCLUSIONS}

This study has demonstrated the importance of determining degradation by-

579 products generated during sewage treatment and their correlation with 580 ecotoxicological assays. Although $100 \%$ removal of the antibiotic amoxicillin was observed in both systems studied (syringes and semi-continuous flow reactor), the formation and accumulation of various by-products was observed, including AMXC,

583 AMXO and AMX-DKP. The rapid hydrolysis of the antibiotic and consequent 584 formation of these compounds led to inhibitions in the production of biogas in the first 585 days of experiment using glass syringes, whereas the effect of the accumulation of 586 recalcitrant by-products to the anaerobic treatment only appeared in the semi587 continuous flow reactor 25 days after the first addition of the pollutant when an abrupt 588 drop in $\mathrm{pH}$ and alkalinity was observed. 
The presence of compound AMX-DKP IV in the BioStat was related to changes in physico-chemical variables. The increase in its concentration led to a growth stimulation of algae $R$. subcapitata but to a reduction in the number of germinated lettuce (L. sativa) seeds and its average root length. On the other hand, studies involving the species $A$. fischeri indicated successive increases in the toxicity of the treated effluent, regardless by-products accumulation and/ or elimination that were formed in the reactor during its operation. The high inhibition observed for this species was related to unbalanced conditions in $A D$ which culminated in a substantial reduction in COD removal, estimated by-product accumulation of $76 \%$ (in relation to the influent amoxicillin concentration) and a two-fold increase in the VFA/ bicarbonate alkalinity ratio in relation to the system without addition of amoxicillin, indicating the accumulation of volatile fatty acids, and therefore, the occurrence of disturbances in the process of anaerobic digestion.

It is thus noted the importance and advantages of performing ecotoxicological assays using organisms of different trophic levels as a way to classify effluents for proper disposal, reuse or design of tertiary treatment systems. Although still an incipient field in many countries, the assessment of effects on aquatic organisms is often a quick, simple and inexpensive way to provide information about environmental effects of treated effluents and should be considered as an important parameter in regulatory frameworks.

\section{ACKNOWLEDGES}

612 We would like to thank Coordenação de Aperfeiçoamento de Pessoa de Nível 613 Superior (CAPES, PGCI 002/2015, Process 004/2016) and Newton Fund (Process 614 172728076)

\section{REFERENCES} Andreozzi, R. et al., 2004. Antibiotics in the Environment: Occurrence in Italian STPs, Fate, and

619 Preliminary Assessment on Algal Toxicity of Amoxicillin, Environ. Sci. Technol. 38, 6832620 6838. https://doi.org/10.1021/es049509a.

621 APHA, Standard Methods for the Examination of Water and Wastewater. 2012. American Public 622 Health Association, Water Environmental Federation, Washington, DC, USA, 22nd edition. 
623 Aydin, S., Ince, B., Ince, O., 2015. Development of antibiotic resistance genes in microbial 624 communities during long-term operation of anaerobic reactors in the treatment of pharmaceutical 625 wastewater, Water Res. 83, 337-344. https://doi.org/10.1016/j.watres.2015.07.007.

626 Bush, K., 2003. $\beta$-lactam antibiotics: Penicillin, and other $\beta$-lactam antibiotics. In: Finch, R.G., 627 Greenwood, D., Norrby, S.R., and Whitley, R.J., Antibiotic and Chemotherapy: antiinfective agents 628 and their use in therapy. 8th ed. Philadelphia (USA): Churchill Livingstone, an imprint of Elsevier 629 Science Limited, pp. 215-216.

630 Çelebi, H., Sponza, D. T., 2012. Comparison of the sensitivities of fish, Microtox and Daphnia-magna 631 bioassays to amoxycillin in anaerobic/aerobic sequential reactor systems, Water Sci. Technol. 66, 632 1117-1131. https://doi.org/10.2166/wst.2012.293.

633 Di Nica, V., Villa, S., Finizio, A., 2017. Toxicity of individual pharmaceuticals and their mixtures 634 to Aliivibrio fischeri: Experimental results for single compounds and considerations of their 635 mechanisms of action and potential acute effects on aquatic organisms, Environ. Toxicol. Chem. 36, 636 807-814. https://doi.org/10.1002/etc.3568.

637 Fountoulakis, M., Stamatelatou, K., Lyberatos, G., 2008. The effect of pharmaceuticals on the kinetics 638 of methanogenesis and acetogenesis, Bioresour. Technol. 99, 7083-7090. 639 https://doi.org/10.1016/j.biortech.2008.01.008.

640 Gozlan, I., Rotstein, A., Avisar, D., 2013. Amoxicillin-degradation products formed under controlled 641 environmental conditions: Identification and determination in the aquatic environment, Chemosphere 642 91, 985-992. https://doi.org/10.1016/j.chemosphere.2013.01.095.

643 Hillis, D.G. et al., 2011. Effects of Ten Antibiotics on Seed Germination and Root Elongation in Three 644 Plant Species, Arch. Environ. Con. Tox. 60, 220-232. https://doi.org/10.1007/s00244-010-9624-0.

645 Hirsch, R. et al., 1999. Occurrence of antibiotics in the aquatic environment. Sci. Total Environ. 225, 646 109-118. https://doi.org/10.1016/S0048-9697(98)00337-4.

647 Hirte, K. et al., 2016. New hydrolysis products of the beta-lactam antibiotic amoxicillin, their pH648 dependent formation and search in municipal wastewater, Water Res. 88, 880-888. 649 https://doi.org/10.1016/j.watres.2015.11.028.

650 ISO 11734, International Organization for Standardization, 1995. Water quality - Evaluation of the 651 "ultimate" anaerobic biodegradability of organic compounds in digested sludge - Method by 652 measurement of the biogas production.

653 ISO 11348-3, International Organization for Standardization, 2007. Water quality - Determination of 654 the inhibitory effect of water samples on the light emission of Vibrio fischeri (Luminescent bacteria test) 655 - Part 3: Method using freeze-dried bacteria.

656 Lallai, A., Mura, G., Onnis, N., 2002. The effects of certain antibiotics on biogas production in the 657 anaerobic digestion of pig waste slurry, Bioresource Technol. 82, 205-208. 658 https://doi.org/10.1016/S0960-8524(01)00162-6.

659 Loos, R. et al., 2018. Review of the $1^{\text {st }}$ Watch List under the Water Framework Directive and 660 recommendations for the $2^{\text {nd }}$ Watch List, EUR 29173 EN, Publications Office of the European Union, 661 Luxembourg. 
662 Magdaleno, A. et al., 2015. Effects of six antibiotics and their binary mixtures on growth of

663 Pseudokirchneriellasubcapitata, Ecotox. Environ. Safe. 113, 72-78.

664 https://doi.org/10.1016/j.ecoenv.2014.11.021.

665 Marcelino, R.B.P. et al., 2016. Evaluation of aerobic and anaerobic biodegradability and toxicity 666 assessment of real pharmaceutical wastewater from industrial production of antibiotics, Braz. J. Chem.

667 Eng. 33, 445-452. http://dx.doi.org/10.1590/0104-6632.20160333s20150136.

668 Meng, L. et al., 2015. Influence of the amoxicillin concentration on organics removal and microbial 669 community structure in an anaerobic EGSB reactor treating with antibiotic wastewater, Chem. Eng. J.

670 274, 94-101. https://doi.org/10.1016/j.cej.2015.03.065.

671 Meng, L. et al., 2017. Amoxicillin effects on functional microbial community and spread of antibiotic 672 resistance genes in amoxicillin manufacture wastewater treatment system, J. Environ. Sci. 61, 110673 117. https://doi.org/10.1016/j.jes.2017.09.020.

674 Mutiyar,P.K., Mittal, A.K., 2013. Occurrences and fate of an antibiotic amoxicillin in extended aeration675 based sewage treatment plant in Delhi, India: a case study of emerging pollutant. Desalin. Water 676 Treat. 51, 6158-6154. https://doi.org/10.1080/19443994.2013.770199.

677 Nägele, E. and Moritz, R., 2005. Structure Elucidation of Degradation Products of the Antibiotic 678 Amoxicillin with Ion Trap MS $^{n}$ and Accurate Mass Determination by ESI TOF, J. Am. Soc. Mass 679 Spectr. 16, 1670 -1676. https://doi.org/10.1016/j.jasms.2005.06.002.

680 OECD, Organisation for Economic Co-operation and Development, 2004. Test no. 202: Daphnia sp. 681 Acute Immobilisation Test, OECD Guidelines for the Testing of Chemicals, Section 2, OECD 682 Publishing, Paris.

683 OECD, Organisation for Economic Co-operation and Development, 2011. Test no. 201: Freshwater 684 Alga and Cyanobacteria, Growth Inhibition Test, OECD Guidelines for the Testing of Chemicals, 685 Section 2, OECD Publishing, Paris.

686 Pérez-Parada, A. et al., 2011. Behavior of amoxicillin in wastewater and river water: identification of its 687 main transformation products by liquid chromatography/ electrospray quadruple time-of-flight mass 688 spectrometry, Rapid Commun. Mass Sp. 25, 731-742. https://doi.org/10.1002/rcm.4902.

689 Petrović, M. et al., 2014. Determination of 81 pharmaceutical drugs by high performance liquid 690 chromatography coupled to mass spectrometry with hybrid triple quadrupole-linear ion trap in different 691 types of water in Serbia. Sci. Total Environ. 468-469, 415-428. 692 https://doi.org/10.1016/j.scitotenv.2013.08.079.

693 Rao, R., Kaur, P.S., Nanda, S., 2011. Amoxicillin: a broad-spectrum antibiotic, Int. J. Pharm. Pharm. 694 Sci. 3, 30-37.

695 Rizzo, L. et al., 2009. Heterogenous photocatalytic degradation kinetics and detoxification of an urban 696 wastewater treatment plant effluent contaminated with pharmaceuticals, Water Res. 43, 4070-4078. 697 https://doi.org/10.1016/j.watres.2009.06.046.

698 Salgado, R.M.N. et al., 2010. Analysis of 65 pharmaceuticals and personal care products in 5 699 wastewater treatment plants in Portugal using a simplified analytical methodology, Water Sci. Technol. 700 62, 2862-2871. https://doi.org/10.1007/s11356-011-0693-z. 
701 Simazaki, D. et al., 2015. Occurrence of selected pharmaceuticals at drinking water purification plants 702 in Japan and implications for human health, Water Res. 76, 187-200. 703 https://doi.org/10.1016/j.watres.2015.02.059.

704 Souza, T.S.O., Foresti, E., 2013. Sulfide-Oxidizing Autotrophic Denitrification: an Evaluation for 705 Nitrogen Removal from Anaerobically Pretreated Domestic Sewage. Appl. Biochem. Biotechnol. 170, 706 1094-1103. https://doi.org/10.1007/s12010-013-0261-8.

707 Torres, P., 1992. Desempenho de um reator de manta de lodo (UASB) de bancada no tratamento de 708 substrato sintético simulando esgotos sanitários. MSc thesis, University of São Paulo, São Carlos, 709 Brazil.

710 USEPA, United States Environmental Protection Agency (EPA 712-C-96-154), 1996. Ecological 711 Effects Test Guidelines - OPPTS 850.4200 - Seed Germination/Root Elongation Toxicity Test.

712 Van Loosdrecht, M. C. M. et al., 2016. Experimental Methods in Wastewater Treatment. London: 713 IwaPublishing, $362 \mathrm{p}$.

714 Verlicchi, P., Al Aukidy, M., Zambello, E. 2012. Occurrence of pharmaceutical compounds in urban 715 wastewater: Removal, mass load and environmental risk after a secondary treatment - A review, Sci. 716 Total Environ. 429, 123-155. https://doi.org/10.1016/j.scitotenv.2012.04.028. 